staff of a hospital. They joined the staff just as I acted as "devil," in the hope of getting good for themselves by so doing. And if any have failed it has probably been their own fault as it was mine.

$$
\text { Yours faithfully, }
$$

London Hospital,

Whitechapel, E., August 24, 1910 SydNey Holland.

\section{GAS AND ELECTRICITY}

To the Editor of The Hospital.

Sin,-My attention has been called to a paragraph appearing in your issue of the 13 th inst., relative to the contract recently entered into by the Finsbury Borough Council with the Gas Light and Coke Co. for the lighting of the Borough. You state that "this decision was taken after the latest examples of gas and electric lighting had been carefully inspected and their relative costs considered."

I am not in a position to say what were the latest examples of gas and electric lighting inspected by the Council, but I do know that my Company offered to submit examples of electric lighting free of expense to the Council, and this offer was declined. With regard to the question of relative running costs, my company submitted a tender for lighting which gave an illuminating power three times as great as the existing gas lighting, and moreover, showed a saving in running costs as compared with gas of over 14 per cent. In spite of this, however, the company's offer was declined. In view of the mistaken impresion which the paragraph in question is likely to convey to your readers, I trust you will find space for this. letter in your next issue.-Yours truly, H. B. Revwick.

(General Manager and Secretary),

The County of London Electric Supply Co., Ltd. August 18, 1910.

\section{NEW APPLIANCES \& THINGS MEDICAL.}

[We shall be glad to receive at our Office, $28 \& 29$ Southampton Street Strand, London, W.O., from the manufacturers, specimens of all new preparations and appliances.]

\section{NONAL ALE AND STOUT.}

(Nonal Company, Ltd., Fulham, London, S.W.)

We have received samples of these ales and stouts, manufactured by the Nonal Company, Ltd., according to Kuhn's patent, and stated to be non-alcoholic. We doubt whether the ordinary person who is not a connoisseur in drinks will be able to tell the difference between these products-especially the ale-and the ordinary ales and stouts sold over the bar. They possess an agreeable, palatable taste, and certainly rank as excellent malt liquors, with the bitter flavour decidedly apparent. The amount of alcohol they contain is very small, and they do not show any trace of extraneous preservative. Both samples submitted to us compared very favourably with samples of ordinary ale and stout so far as the amount of food material present was concerned, except that the amount of sugar present in the Nonal ale was slightly above that to be found in ordinary ale. Those who object to malt liquors on the score of their alcoholic content will do well to give these productions a thorough trial. For convalescents especially we should imagine Nonal stout to be an excellent drink.

\section{DIGESTIN.}

(Burgoyne, Burbidges \& Co., 12 and 16 Coleman Street, London, E.C.)

Digestin is a vegetable enzyme derived from the Okazaki fungus, an aspergillus with a peculiar mycelium which grows in the Far East, and is prepared in the pharmaceutical laDoratory of Messrs. Yenjo Shoten, Ltd., at Somei, Sugamo, near Tokio, in Japan. It is a yellowish-white, odourless, practically tasteless hygroscopic powder, the dose of which is, for adults, from 0.1 to 0.3 gram, taken with water immediately after a meal. It is stated to be a very powerful proteid digestant, acting equally well in acid and alkaline media. The samples supplied to us were foundeto possess marked proteolytic and inverting properties. The invert action was specially marked in a neutral medium when the powder was allowed to act upon dry potato-flour. This digestant appears to us to be well worth a thorough trial, as it is easily taken by children, and is undoubtedly preferable-so far at least as can be judged from test-tube experiments - to other vegetable and animal enzymes on the market. The agents are Messrs. Burgoyne, Burbidges \& Co., of 12 and 16 Coleman Street, E.C. The price of the samples was not stated.

\section{For Hospitals and Institutions.}

Analysis Ledger. 3 vols. (Uniform with the new Index of Classification adopted by the

King's Hospital Fund) .... ... ...

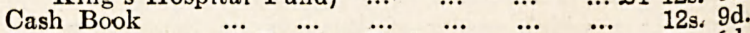

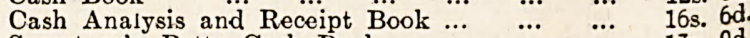
Secretary's Petty Cash Book ... $\quad . . . \quad \ldots . \quad$ 13s. 0d.

List or Register of Annual Subscribers ... $\quad . . . £ 1$ 0s. Od.

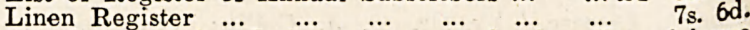

And many other Ledgers necessary in the office of $\operatorname{larg} \theta$ and small institutions.

Of all booksellers or of The Scientific Press, Limited, 28 and 29 Southampton Street, Strand, Iondon, W.C.

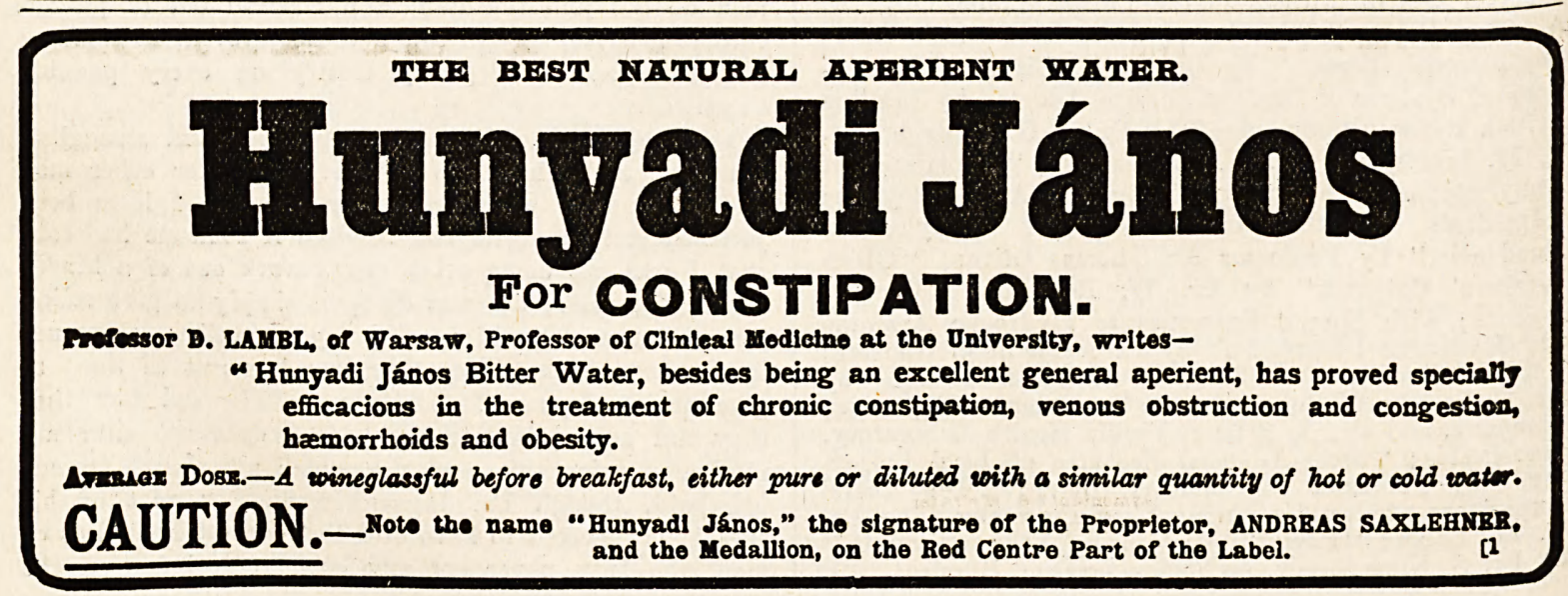

